\title{
HISTÓRIA DA EDUCAÇÃO MATEMÁTICA EM PERSPECTIVA IBEROAMERICANA: RELAÇÕES ENTRE CAMPO DISCIPLINAR E CIÊNCIAS DA EDUCAÇÃO
}

Wagner Rodrigues Valente ${ }^{1}$

No Brasil, desde a década de 1990, com os chamados Parâmetros Curriculares Nacionais - PCN (BRASIL, 1998), tem-se a inclusão das possibilidades didático-pedagógicas da História da Matemática no ensino. Em realidade, livros didáticos das primeiras décadas do século XX, vez por outra, utilizaram referências à História da Matemática para o ensino dessa disciplina (MIGUEL; MIORIM, 2004). Porém, em razão desse reconhecimento oficial curricular, pelos PCN, passou-se a uma maior valorização e incremento de estudos sobre o papel da História da Matemática no ensino de matemática nas últimas décadas. A História da Matemática, dessa maneira, firmou-se como,

\footnotetext{
${ }^{1}$ Universidade Federal de São Paulo - Campus Guarulhos (Unifesp), Guarulhos/SP, Brasil.
} 
eminentemente, um expediente didático a serviço do ensino de matemática.

Se as últimas décadas viram o enorme crescimento de estudos sobre o uso didático da História da Matemática no âmbito escolar, integrando o saber profissional do professor de Matemática, isso parece não ter sido acompanhado pela pesquisa em História da Matemática. No seio mesmo dos congressos e reuniões relativos à História da Matemática mais e mais vem circulando, em número bastante significativo, trabalhos sobre História da educação matemática - Hem². Um estudo realizado por Mendes (2014) revelou que mais da metade de todos os trabalhos escritos no âmbito da História da Matemática, de 1990 a 2010, no Brasil, em realidade, não trataram de História da Matemática; referiram-se a estudos de História da educação matemática. E, ao que tudo indica, na década seguinte, essa tendência tornou-se ainda mais acentuada, com crescimento exponencial de estudos sobre Hem. Essa representatividade de modo crescente das pesquisas sobre Hem veio a permitir a criação de congressos nacionais e internacionais sobre História da educação matemática3.

Também, a criação de revistas especializadas em Hem, com destaque para a Histemat - Revista de História da Educação Matemática, órgão da própria Sociedade Brasileira de História da Matemática. Por fim, nesse movimento da Hem, tem-se a sistematização de trabalhos, estudos e resultados de pesquisas de modo a formarem um conjunto de saberes para a formação de licenciandos, conduzindo à criação de uma disciplina intitulada "História da educação matemática" 4 . Todos esses elementos, dentre outros, vão permitindo a

${ }^{2}$ Aqui utilizamos a expressão "História da educação matemática - Hem" e não "História da Educação Matemática" de modo a não ensejar dúvidas quanto às possibilidades de estudos da Hem. Elas não se restringem às pesquisas que tratam da história do campo da Educação Matemática, referem-se a toda e qualquer investigação que considere a matemática presente nos processos de ensino e de aprendizagem ao longo dos séculos.

3 Citem-se, por exemplo, os Enaphem - Encontro Nacional de Pesquisa em História da Educação Matemática, que promoverá em 2020 a sua quinta edição de modo virtual, em razão da pandemia; os Cihem - Congresso Iberoamericano de História da Educação Matemática, que realizou V Cihem, em 2019, em Bogotá, Colômbia.

4 A revista Cadernos de História da Educação, em seu volume 16, n. 3, de 2017, publicou um Dossiê reunindo artigos que tratam da institucionalização da História da Educação Matemática como disciplina de formação dos cursos de licenciatura em Matemática em diferentes universidades brasileiras. Para maiores detalhes leiam-se os textos no endereço: 
caracterização de uma nova seara disciplinar: a História da educação matemática.

De outra parte, o movimento de constituição desse novo campo profissional e de pesquisas, ainda apresenta resistências e fragilidades. As resistências à sua constituição parecem ter origem, muito menos na rejeição de necessidade de estabelecimento de uma disciplina formativa na grade curricular dos cursos de licenciatura e, muito mais, no debate sobre quais saberes já sistematizados por pesquisas da Hem deverão compor essa disciplina. Isso indica que ainda há uma instabilidade e não consenso sobre quais saberes vindos da Hem deveriam ser utilizados na formação docente5.

Em termos de fragilidades, desde 2014, pelo menos, tem sido apontado que há um elemento importante que ainda resta para sedimentar como campo disciplinar a Hem, ele ainda não foi devidamente explicitado pelos estudos da Hem, e tem caráter epistemológico: quais são seus problemas específicos, as problemáticas próprias à Hem, não tratados por outras searas disciplinares. Essa crítica foi abordada com ênfase desde o livro síntese do I Enaphem, Encontro Nacional realizado em 2012, onde é possível ler:

A maioridade da história da educação matemática, ao que tudo indica,
terá como caminho a trilhar aquele de transformar-se da condição de
especialidade, seja da História da Matemática, da Educação
Matemática, ou mesmo da História/História da Educação, para a
plenitude de um campo científico, erigindo-se como disciplina. E para
isso será necessária a ultrapassagem de objetos de pesquisa - que
hoje, em boa medida, vêm sendo tomados do real empírico, de sua
aparência fenomenológica (níveis escolares do ensino de matemática,
conteúdos de ensino matemático, formação de professores de
matemática, metodologias etc. são exemplos disso) [...] para a

http://www.seer.ufu.br/index.php/che/issue/view/1529.

5 Houve debates acalorados em tempo da realização do III Enaphem, em 2016, cujo tema principal justamente tratou da História da educação matemática na formação de professores de matemática. Tais debates, em boa medida, foram motivados pela apresentação de ementas e referências bibliográficas que diversos pesquisadores estavam utilizando em seus cursos de Hem. Determinados grupos de pesquisa, na ocasião, ao não verem contemplados os seus estudos nessas referências, mostraram-se contrários à constituição da Hem como disciplina de formação em cursos de licenciatura. 
construção teórica de objetos de conhecimento (VALENTE, 2014, p. 330).

A caracterização dos problemas próprios à História da educação matemática envolve, dentre outras coisas a maior clareza de como esse possível novo campo se relaciona com campos vizinhos a ele como, por exemplo, História da Matemática e a História da Educação, de modo a que se possa ter clareza sobre problemas próprios da História da educação matemática.

A chamada internacional para textos a este Dossiê intitulado "História da educação matemática" permite, de algum modo, perceber como, para além do debate nacional, outros pesquisadores vêm elaborando suas investigações no âmbito da Hem. No caso dos textos aprovados para esta publicação é possível uma amostra significativa do panorama iberoamericano desses trabalhos. Portugal, Espanha, Argentina, Brasil e Venezuela participam da coleção de textos publicados neste Dossiê.

O primeiro texto do Dossiê intitulado "O currículo escolar sob o olhar da História Cultural e a modernização do ensino da aritmética na escola primária paranaense no início do século XX" escrito por Neuza Bertoni Pinto traz uma análise das relações que envolvem a produção do currículo escolar. Penetra no âmago dos debates e das circunstâncias que tornam inteligíveis como se estabelecem as relações entre os saberes disciplinares (matemática-aritmética) e a pedagogia que, num dado tempo, fixa as finalidades do ensino escolar. Para tal, mobiliza autores da História Cultural de modo a explicitar as transformações da aritmética na escola paranaense no início do século XX.

O segundo texto do Dossiê, escrito por Wagner Rodrigues Valente e Maria Célia Leme da Silva, intitulado "História da Educação Matemática no curso primário e formação de professores no Brasil”, mostra resultados de trabalhos que vêm sendo realizados em âmbito coletivo pelo Grupo Associado de Estudos e Pesquisas em História da Educação Matemática - Ghemat Brasil. A História da educação matemática é tratada, do mesmo modo que o artigo de 
Bertoni Pinto, a partir das relações entre o campo disciplinar matemático e a pedagogia, tendo em conta o ensino e a formação de professores para o curso primário. $\mathrm{O}$ esforço em avançar teoricamente situa-se em mobilizar categorias como "matemática a ensinar" e "matemática para ensinar", conceitos que vêm sendo construídos pelo Grupo em seus projetos coletivos de pesquisa. As análises ao longo do tempo das relações entre essas duas matemáticas - a ensinar e para ensinar - indicam um caminho que pode melhor caracterizar problemáticas de pesquisa próprias à Hem.

A pesquisadora argentina Alejandra Deriard participa do Dossiê com o texto "Manuais em Buenos Aires (1967-1987) na busca de uma 'vulgata escolar': uma narrativa de um processo de iniciação em pesquisa”. Semelhantemente ao estudo de Bertoni Pinto, mobiliza autores da História Cultural, descrevendo seu processo de pesquisa de modo a caracterizar como, num dado período, na Argentina, tem-se a estabilização da matemática escolar por intermédio de obras que "dizem a mesma coisa, ou quase isso" (CHERVEL, 1990, p. 203), na caracterização que esse autor francês faz de uma "vulgata escolar". O período analisado refere-se ao que internacionalmente ficou conhecido como Movimento da Matemática Moderna.

Um estudo sobre a Escuela Venezolana para la Enseñanza de la Matemática - Evem é realizado pelos pesquisadores Cinthia del Carmen Humbría Burgos e Fredy Enrique González no quarto artigo do Dossiê. A análise desse espaço complementar de formação de professores - a Evem - permitiu levar os autores a trazer para a cena principal do texto os processos de consolidação da Educação Matemática como campo profissional e de pesquisa na Venezuela.

O estudo das professoras espanholas Dolores Gallego e Pilar Olivares traz ao Dossiê História da Educação Matemática a análise dos materiais didáticos Discat. O nome, como explicam as autoras, vem do Instituto J. J. Rousseau e da Maison des Petits: Discat a puero magister - "que o professor aprenda com o aluno”. Um material idealizado para materializar as propostas da 
educação funcional de Édouard Claparède. Por intermédio da análise desse elemento da cultura material escolar, surgem as complexas relações pedagógicas mantidas entre Espanha e Suíça nas primeiras décadas do século XX. Nessa análise, também está presente a circulação desses materiais e as empresas que os fabricavam.

Penetrar na caixa preta da sala de aula em diferentes tempos escolares é lema de qualquer historiador da educação. O mesmo é válido para historiadores da educação matemática. $\mathrm{O}$ estudo elaborado pelos professores portugueses José Manuel Matos e Alexandra Sofia Rodrigues "Matemática na sala de aula, um estudo histórico-iconográfico" é exemplo que persegue o lema. Os autores analisam imagens (fotografias, gravuras e figuras) que foram obtidas em coleções bibliográficas, arquivos e em uma revista. Utilizando um paradigma qualitativo (Erwin Panofsky), com pesquisa histórica e documental, os autores mostram, que subsídios amparavam as aulas desde tempos medievais até meados do século XX.

A leitura e síntese dos textos do Dossiê mostra que, em âmbito iberoamericano, a História da educação matemática vem se firmando como uma nova disciplina científica. De algum modo, cada um dos textos revela que não é pelo estudo matemático em si mesmo e pela história de sua produção, nem tampouco por didáticas gerais, que a Hem poderá estabelecer os seus próprios problemas de pesquisa. Os caminhos para isso vêm sendo pavimentados pela problematização, ao longo do tempo, das relações estabelecidas entre os campos disciplinares - no caso, a matemática - e as ciências da educação.

\section{REFERÊNCIAS}

BRASIL. Secretaria de Educação Fundamental. Parâmetros curriculares nacionais: Matemática / Secretaria de Educação Fundamental. Brasília: MEC / SEF, 1998.

CHERVEL, André. História das disciplinas escolares: reflexões sobre um campo 
de pesquisa. Teoria \& Educação, Porto Alegre/RS, n. 2, p. 177-229, 1990.

\section{MENDES, Iran Abreu. Cartografias da produção em História da}

Matemática no Brasil: um estudo centrado nas dissertações e teses

defendidas entre 1990-2010. 2014. Relatório de Pesquisa (Bolsa produtividade CNPq) - Universidade Federal do Rio Grande do Norte, Natal, 2014.

\section{MIGUEL, Antônio; MIORIM, Maria Ângela. História na Educação}

Matemática: propostas e desafios. Belo Horizonte: Autêntica, 2004. (Coleção Tendências em Educação Matemática).

VALENTE, Wagner. Rodrigues. História da Educação Matemática no Brasil - Problemáticas de pesquisa, fontes, referências teórico-metodológicas e histórias elaboradas. São Paulo: L. F. Editorial, 2014.

WAGNER RODRIGUES VALENTE é Professor Associado Livre Docente do Departamento de Educação da Escola de Filosofia, Letras e Ciências Humanas da Universidade Federal de São Paulo (Unifesp), Campus Guarulhos, SP (2010). Doutor em Educação pela Faculdade de Educação da Universidade de São Paulo e Institut National de Recherche Pédagogique (INRP) de Paris (1997). Mestre em História e Filosofia da Educação pela Pontifícia Universidade Católica de São Paulo (1991). Graduado em Engenharia pela Escola Politécnica da Universidade de São Paulo (1979). Presidente do Grupo Associado de Estudos e Pesquisas sobre História da Educação Matemática Ghemat Brasil (ghemat-brasil.com) (gestão 2018-2021).

E-mail: ghemat.contato@gmail.com

(D) http://orcid.org/0000-0002-2477-6677

Recebido em: 02 de janeiro de 2020

Aprovado em: 22 de abril de 2020

Revista História da Educação - RHE

Associação Sul-Rio-Grandense de Pesquisadores em História da Educação - Asphe

Artigo de acesso aberto distribuído nos termos de licença Creative Commons. 